\title{
Erratum to: The Horizontal Metropolis Between Urbanism and Urbanization
}

\author{
Paola Viganò, Chiara Cavalieri and Martina Barcelloni Corte
}

\section{Erratum to:}

P. Viganò et al. (eds.), The Horizontal Metropolis

Between Urbanism and Urbanization, https://doi.org/10. 1007/978-3-319-75975-3

Incorrect chapter title "Genius of Utopia: The Evolutionary Nature of Genius" has to be corrected as "Genius of Utopia: The Evolutionary Nature of Genius Loci".

The following Part Introductions "Horizontal Metropolis: Theories and Roots, a Transcultural Tradition: Introduction", "Horizontal Metropolis: Spatial, Social and Natural Capital: Introduction", and "The Horizontal Metropolis: Issues and Challenges of a New Urban Ecology: Introduction", Conclusion "The Horizontal Metropolis Needs a Soul Rereading the Book "Zwischenstadt" After Twenty Years", and Afterword "12 Points from a Roundtable" have been reissued as chapters of the book. They were previously listed as Part introductions and end matter without author attribution. No content within the chapters has been changed

The updated online version of these chapters can be found at https://doi.org/10.1007/978-3-319-75975-3_7

https://doi.org/10.1007/978-3-319-75975-3_40

https://doi.org/10.1007/978-3-319-75975-3_41

https://doi.org/10.1007/978-3-319-75975-3_42

https://doi.org/10.1007/978-3-319-75975-3_43

https://doi.org/10.1007/978-3-319-75975-3_44

https://doi.org/10.1007/978-3-319-75975-3_45

https://doi.org/10.1007/978-3-319-75975-3 